\title{
Морфология, химический состав и U-Pb возраст циркона из пород гнейсового комплекса участков Перевал, Полигонный и Малонемецкая бухта (северо-запад Кольского региона)
}

\author{
Ниткина Е.А., Каулина Т.В. \\ Геологический институт КНЦ РАН, Anamuты, nitkina@rambler.ru; kaulina@geoksc.apatity.ru
}

\begin{abstract}
Аннотация. В статье приводится геология детальных участков, расположенных в северо-западной части Центрально-Кольского составного террейна Балтийского щита. Наиболее древними породами в районе являются гранат-биотитовые гнейсы, в которых внедрялись габброиды; на контакте с габброидами развиты тела кварцевых метасоматитов; также встречаются гранодиориты с секущими пегматитовыми и аплитовыми жилами. Для всех пород выделены магматичекая, метаморфическая и метасоматическая генерации циркона. Временная шкала геологических процессов определена датированием циркона различных генераций: 2.8 млрд. лет - время метаморфизма гранат-биотитовых гнейсов, $2722 \pm 9$ млн. лет - кристаллизации гранодиоритов; $2636 \pm 41$ млн. лет - образование плагиоаплитов, $2620 \pm 16$ млн. лет - внедрение пегматитов, $2587 \pm 5$ млн. лет - внедрение габброидов, 2522-2503 млн. лет - образования кварцевых метасоматитов, $2507 \pm 7$ млн. лет - метаморфизм, рассланцевание и будинирование габброидов.
\end{abstract}

Ключевые слова: изотопное U-Pb датирование; минералогия циркона; архейский комплекс Балтийского щита.

\section{Morphology, chemical composition and U-Pb age of zircon from the gneissic complex of the Pereval, Poligonniy and Malonemetskaya bay areas (NE Kola region)}

\author{
Nitkina E.A., Kaulina T.V. \\ Geological institute KSCRAS, Apatity,nitkina@rambler.ru; kaulina@geoksc.apatity.ru
}

\begin{abstract}
The article reviews geological setting of the Poligonniy, Pereval and Nemetskaya bay areas, which are situated at the Central-Kola terrain. Garnet-biotitic gneisses are the most ancient rocks in this area. Gneisses contain gabbro intrusion with quartz matosomatites widespread along the contact; also granodiorites cut by pegmatite and aplite veins are reported. Zircons from all rocks were divided into magmatic, metamorphic and metasomatic type. The geological processes time scale is determined by ziron dating: $2.8 \mathrm{Ga}$ - metamorphism of garnet-biotitic gneisses, $2722 \pm 9 \mathrm{Ma}$ - crystallization of granodiorites; $2636 \pm 41 \mathrm{Ma}$ - granite and 2620 $16 \mathrm{Ma}$ pegmatite emplacement, $2587 \pm 5 \mathrm{Ma}$ - gabbro crystallisation, $2522-2503 \mathrm{Ma}$ - origin of quartz metosomatites, $2507 \pm 7 \mathrm{Ma}$ - gabbro metamorphism, shearing and boudinage.
\end{abstract}

Key words: isotope U-Pb zircon dating; zircon mineralogy; Achaean complex of the Baltic Shield.

\section{Введение}

Участки Полигонный,Перевали Малонемецкая Бухтарасположены натерритории Мурманской области и приурочены к Центрально-Кольскому составному террейну (рис. 1), сложенному гранитогнейсами и мигматитами с реликтами биотит-плагиоклазовых, биотит-амфибол-плагиоклазовых гнейсов, амфиболитов, гранат-биотит-плагиоклазовых гнейсов (Балаганский, 2002; Козлов и др., 2006). Возраст наиболее раннего метаморфизма пород Кольской серии $-2830 \pm 10$ млн. лет,

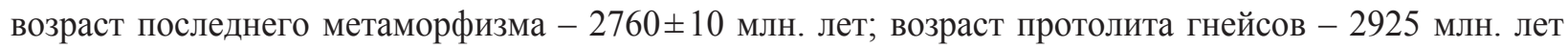
(Mitrofanov et al., 1995). По структурно-метаморфической шкале Н.Е. Козловой (личное сообщение) самыми древними породами участков являются гранат-биотитовые гнейсы, в которые были внедрены габброиды; на границе метагабброидов и гнейсов развиты тела кварцевых метасоматитов. В пределах участка Малонемецкая бухта встречаются гранодиориты с возрастом $2722 \pm 9$ млн. лет (Козлов и др., 2007), секущиеся пегматитовыми жилами.

Целью работы являлось изучение минералогии циркона и определение возрастной последовательности геологических процессов, проявленных на участках. 


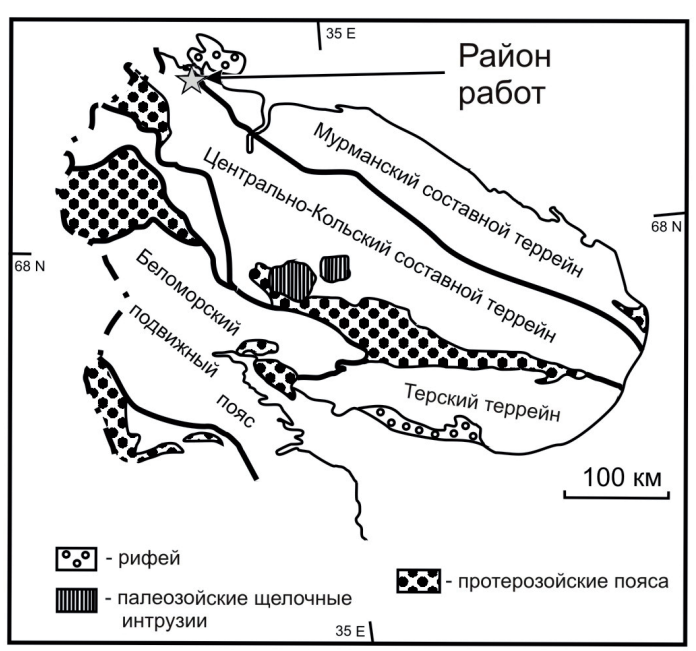

Рис. 1. Схематическая карта Кольского региона по (Балаганский, 2002).

Fig. 1. Geological scheme of the Kola region after (Balaganskiy, 2002).

\section{Геологическое положение участков Перевал, Полигонный и Малонемецкая бухта}

Участок Полигонный сложен гранитами, гранат-биотитовыми гнейсами, ставролит-гранатбиотитовыми гнейсами и пегматитами (Козлов и др., 2006). Для U-Pb изотопных исследований были отобраны гранат-биотитовые гнейсы (проба NVII - 12 кг), являющиеся самыми древними породами, представленными на участке, а также пегматит (проба NV 2.35 кг), связанный со вторым этапом деформаций пород участка.

В пределах участка Перевал представлены гранат-биотитовые и биотитовые гнейсы, сланцеватые амфиболиты с гранатом, магнетит-кварцевые и кварц-силикатные метасоматиты, образовавшиеся в телах габброидов в процессе метаморфизма (на границе гнейсов и амфиболитов), гранатовые пегматиты, аплиты и дайки метадолеритов (Козлов и др., 2006).

Для $\mathrm{U}-\mathrm{Pb}$ исследований были отобраны метаморфизованные габброиды (проба NII - 27.7 кг), связанные с первым этапом магматизма и кварцевые метасоматиты (проба NIII - 25.3 кг), образование которых связано с этапом метаморфизма и деформаций.

Участок Малонемецкая Бухта сложен мигматизированными биотит-амфиболовыми и биотитовыми гнейсами с прослоями железистых кварцитов (Козлов и др., 2006). Возраст гранодиоритов, определенный U-Pb методом по циркону, равен $2722 \pm 9$ млн. лет (Козлов и др., 2007). На геохронологическое исследование были отобраны пробы плагиоаплитов (проба А-1 - 2.5 кг) и пегматитов (проба П-1 - 3.2 кг).

\section{Мeтодика}

Исследования морфологических особенностей кристаллов циркона проводились под бинокуляром по 50-ти зернам, отобранным для каждой пробы из мономинеральной дорожки циркона, и во вторичных электронах в растровом электронном микроскопе; исследование анатомии кристаллов циркона проводилось в иммерсионной жидкости и в полированных препаратах в обратнорассеянных электронах. Морфологические типы кристаллов циркона выделялись по габитусу, окраске и прозрачности. Генерации циркона были выявлены при изучении внутреннего строения кристаллов - зональности, наличию ядер и оболочек, и изменению зон роста (Каулина, 2010).

Измерения содержаний изотопных $U$-Pb отношений проводилось на масс-спектрометре МИ-1201T. Для датирования пород из мономинеральных фракций был отобран циркон различных генераций. Далее из каждой навески по методу (Krogh, 1973) были выделены свинец и уран. Измерения производились на масс-спектрометре МИ-1201Т в лаборатории Геохронологии и геохимии изотопов в ГИ КНЦ РАН, как правило, на плавно спадающем ионном токе; погрешность измерений изотопного состава $\mathrm{Pb}$ составляла $-0.15 \%$ (для отношения ${ }^{206} \mathrm{~Pb} / 204 \mathrm{~Pb}$ от 1 до $5 \%$, в зависимости от его величины); холостое внутрилабораторное загрязнение полного анализа составляло менее 0.2 нг для свинца и 0.05 нг для урана. В изотопном анализе свинца погрешности определений составляли $\pm 0.15 \%$. Погрешности определений концентрации урана и свинца равны $\pm 0.5 \%$.

Вычисление возрастов проведено по принятым величинам констант распада урана, ошибки даны на уровне $2 \sigma$. Все изотопные отношения при расчетах в программе «PBDAT» (Ludwig, 1991) исправлены на масс-дискриминацию, рассчитанную по параллельным анализам стандартов SRM-981 и SRM-982 и равную $0.18 \pm 0.05 \%$. Параметры изохрон рассчитывались в программе «ISOPLOT» (Ludwig, 1999). 


\section{Описание циркона: морфология, анатомия, химический состав и U-Pb возраст}

В биотитовом гнейсе (проба N VII) выделено 2 типа циркона (рис. 2). Первый составляет $80 \%$ и представлен коричневыми прозрачными и полупрозрачными трещиноватыми кристаллами призматического габитуса гиацинтового типа с гранями $\{100\}$ и $\{111\}$. Размер кристаллов $125 \times 50$ $250 \times 125$ мкм (коэффициент удлинения - Ку от 1.2 до 2.5). Также отмечаются кристаллы с гранями $\{110\},\{100\}$ и $\{311\}$, размером $150 \times 100-500 \times 125$ мкм (Ку - от 1.5 до 4). Внутреннее строение характеризуется наличием четырех зон, внешняя из которых по строению схожа с однородными кристаллами второй генерации.

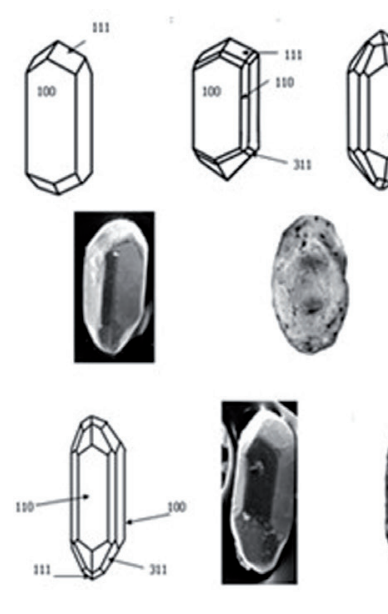

VII 6иотитовый гнейс

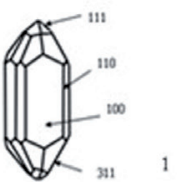

1
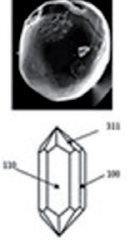

2

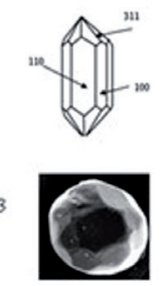

III кварцевый метасоматит
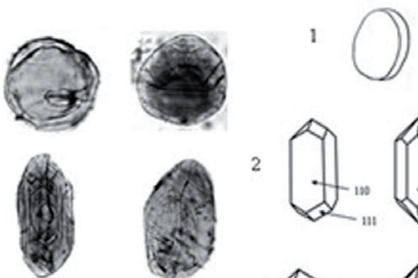

से

3

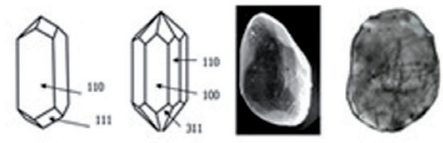

П амфиболит

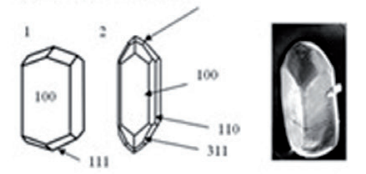

Аплит и Пегматит

Рис. 2. Морфология и анатомия кристаллов циркона. Fig. 2. Morphology and internal structure of zircon.

Второй тип составляет 20 \% и представлен светло-коричневыми прозрачными трещиноватыми кристаллами призматического габитуса с гранями $\{100\},\{110\}$ и $\{111\},\{311\}$ размером $175 \times 75$ $-250 \times 100$ мкм (Ку $-1.7-2.3)$. Предварительный U-Pb возраст метаморфического циркона составляет 2.8 млрд. лет (Nitkina\&Kaulina, 2019).

В амфиболите по габбро (проба N II) выделено три типа циркона (рис. 2): Первый составляет $70 \%$ и представлен мелкими розовыми короткопризматическими прозрачными не трещиноватыми кристаллами со сглаженными ребрами и головками, размером 50×50 - 125×50 мкм (Ку от 1 до 2,5). По внутреннему строению - однородны.

Второй тип составляет $20 \%$ и представлен розовыми прозрачными удлиненными кристаллам гиацинтового типа с гранями $\{100\}$ и $\{111\}$ и размером $200 \times 100-600 \times 125$ мкм (Ку от 2 до 4.8 ); а также кристаллами переходного типа с развитыми гранями $\{100\},\{110\}$ и $\{311\}$, размером $225 \times 750$ - 250×150 мкм (Ку от 1.6 до 3). Циркон характеризуется искривленными ребрами, что свойственно магматическому циркону из основных пород, так как теряется преимущество кристаллизации циркона. Внутреннее строение - однородное.

Третий тип составляет $13 \%$ и представлен коричневыми прозрачными призматическими кристаллами со сглаженными ребрами и головками, размером 75×75-200×100 мкм (Ку от 1 до 2). Кристаллы гиацинтового типа с гранями $\{100\}$ и $\{111\}$, размером $200 \times 150$ мкм (Ку 1.3). Также отмечены кристаллы с развитыми гранями $\{110\},\{100\}$ и $\{311\}$ и размером $250 \times 100$ мкм (Ку 2.5). Установлено развитие иррациональных граней, которые образуются при нарастании однородного циркона в условия амфиболитовой фации метаморфизма. Внутреннее строение характеризуется наличием зональных ядер циркона и однородной каймы.

$\mathrm{U}-\mathrm{Pb}$ возраст магматического циркона по трем точкам равен $2587 \pm 5$ млн. лет и соответствует времени внедрения габброидов; возраст метаморфизма габброидов определен по трем точкам метаморфического циркона и равен $2507 \pm 7$ млн. лет (рис. 3 a). 
В кварцевом метасоматите (проба N III) выделяется 3 типа циркона (рис. 2): Первый составляет $62 \%$ и представлен коричневыми прозрачными удлиненно-призматическими кристаллами со сглаженными ребрами и головками, размером от 75×50 мкм до 50×25 мкм (Ку от 1.5 до 2). Выделяются кристаллы разного размера и огранки: гиацинтового типа с гранями $\{100\}$ и $\{111\}$, размером от $125 \times 100$ мкм до $300 \times 100$ мкм (Ку от 1.25 до 3) и кристаллы призматического габитуса с гранями $\{110\},\{100\}$ и $\{311\}$, размером $75 \times 75-125 \times 100$ мкм (Ку от 1 до 1.25). Циркон первого типа характеризуется развитием иррациональных граней и наличием реликтовых ядер, окруженных зональным цирконом и внешней однородной каймой.

Второй тип составляет $21 \%$ и представлен розовыми прозрачными трещиноватыми кристаллами со сглаженными ребрами и головками, размером $75 \times 75-200 \times 150$ мкм; кристаллами гиацинтового типа с развитыми гранями $\{100\}$ и $\{111\}$, размером $100 \times 75-150 \times 100$ мкм (Ку 1.5$)$ и кристаллами призматического габитуса с гранями $\{110\},\{100\},\{311\}$, размером $75 \times 75-300 \times 150$ мкм (Ку от 1 до 2).

Третий тип циркона составляет 17 \% и представлен розовыми полупрозрачными трещиноватыми изометричными кристаллами с газово-жидкими включениями, размером 100×100 - 250×250 мкм. На кристаллах развито большое количество иррациональных граней, все кристаллы имеют однородное внутреннее строение. Циркон этого морфологического типа образовался в условиях амфиболитовой фации метаморфизма при избытке кремнезема и добавок железа.

$\mathrm{U}-\mathrm{Pb}$ возраст метаморфического циркона равен $2503 \pm 67$ млн. лет; метасоматического циркона определен в $2522 \pm 53$ млн. лет (рис. 3 б). Возрасты перекрываются в пределах ошибки и, учитывая метаморфический и метасоматический генезис циркона, интерпретируется как время образования кварцевых метасоматитов во время амфиболитового метаморфизма.

Плагиоаплит (проба А). В пробе отмечено два типа циркона (рис. 2). Основной объем пробы (85\%) составляют розоватые, длинно- и короткопризматические кристаллы гиацинтового типа с развитыми гранями $\{100\}$ и $\{111\}$ и тонкой магматической зональностью. Размер циркона от 75 до 250 мкм. В меньшем количестве - до $15 \%$ - присутствуют коричневые длиннопризматические кристаллы с развитыми гранями $\{110\},\{100\}$ и $\{311\}$.

Для пяти фракций розового циркона получен возраст $2636 \pm 41$ млн. лет, который отвечает возрасту плагиоаплитов (рис. 3 в).

Пегматит (проба П). В пробе представлены коротко и длиннопризматические кристаллы (рис. 2), в огранке которых преобладает призма $\{100\}>>\{110\}$ и дипирамида $\{111\}>\{311\}$. Окраска циркона варьирует от бесцветной (редкие зерна) до желтой и коричневой. В большинстве своем кристаллы мутные и трещиноватые. Размер зерен до 300 мкм.
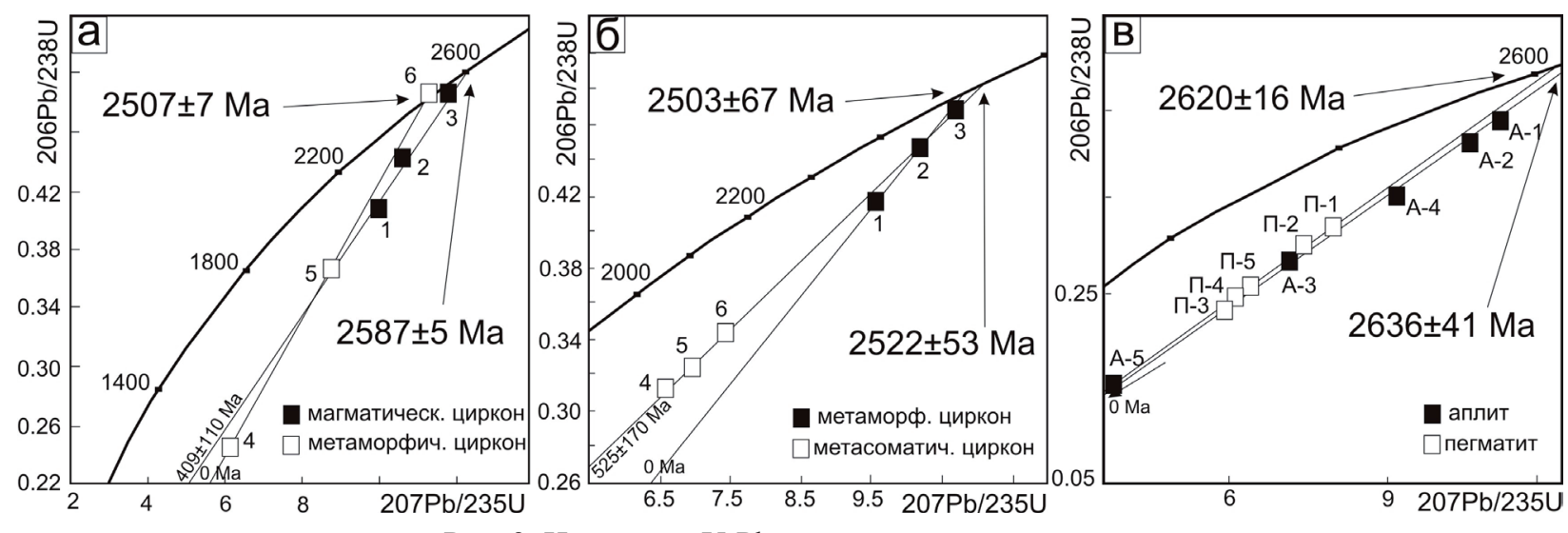

Рис. 3. Изотопная U-Pb диаграмма с конкордией.

a - для циркона из амфиболита (II); б - для циркона из кварцевого метасоматита (III); в - для циркона из аплитов (А1 - А7) и пегматитов (П1 - П5).

Fig. 3. U-Pb isotope plot with concordia.

$\mathrm{a}$ - for zircon from amphibolite (II); $\mathrm{b}$ - for zircon from quartz metasomatite (III); $\mathrm{c}$ - for zircon from aplite (A1 - A7) and pegmatite $(\Pi 1-\Pi 5)$. 
Возраст циркона по пяти точкам равен $2620 \pm 16$ млн. лет и отвечает времени кристаллизации жилы пегматита (рис. 3 в).

Таким образом, для северо-западной части Кольского региона установлена следующая возрастная последовательность геологических процессов: 2.8 млрд. лет - метаморфизм гранат-биотитовых гнейсов, $2722 \pm 9$ млн. лет - кристаллизация гранодиоритов (Козлов и др., 2007); 2636 41 млн. лет - образование плагиоаплитов, $2620 \pm 16$ млн. лет - внедрение пегматитов, $2587 \pm 5$ млн. лет - внедрение габброидов, 2522-2503 млн. лет - образование кварцевых метасоматитов, $2507 \pm 7$ млн. лет - метаморфизм, рассланцевание и будинирование габброидов.

Авторы благодарны за консультации по геологическому строению участков - Д.г.-м.н. Н.Е. Козлову и Н.Е. Козловой, за консультации по минералогии циркона - д.г.-м.н. А.В. Волошину, за РЭМ фотографии и химический анализ циркона - Е.Э. Савченко.

Работа выполнена в рамках темы НИР №0226-2019-0052 и частично поддержана из средств Программы Президиума РАН № 8.

\section{Литература}

1. Балаганский В.В. Главные этапы тектонического развития северо-востока Балтийского щита в палеопротерозое. Автореф. дисс. докт. геол.-мин. наук. СПб. 2002. 32 с.

2. Беляев О.А. Прогрессивный зональный метаморфизм раннего протерозоя северо-запада Кольского полуострова // Метаморфизм докембрийских комплексов (Кольский полуостров). Апатиты. Изд. КФАН CCCP. 1976. C. $31-49$.

3. Козлов Н.Е., Сорохтин Н.О., Глазнев В.Н., Козлова Н.Е., Иванов А.А., Кудряшов Н.М., Мартынов Е.В., Тюремнов В.А., Матюшкин А.В., Осипенко Л.Г. Геология архея Балтийского щита. СПб.: Наука. 2006. 329 C.

4. Козлов Н.Е., Мартынов Е.В., Козлова Н.Е., Каулина Т.В., Смирнов Ю.П. Петрохимическая систематика амфиболитов архейской части разреза Кольской сверхглубокой скважины. Геохимия. 2007. № 2. С. 11-22.

5. Каулина Т.В. Образование и преобразование циркона в полиметаморфических комплексах. Апатиты. Изд-во: КНЦ РАН. 2010. 144 с.

6. Krogh T.E. A low-contamination method for hydrothermal decomposition of zircon and extraction of $\mathrm{U}$ and $\mathrm{Pb}$ for isotopic age determination // Geochim. Cosmochim. Acta. 1973. V. 37. P. 485-494.

7. Ludwig K.R. PBDAT, a comruter program for Processing Pb-U-Th Data, version 1.20, United geological survey open-file report 88-542. 1991.

8. Ludwig K.R. Isoplot/Ex, a geochronological Toolkit for Microsoft Exel, version 2.05: Berkeley Geochronology Center special publication N1a. 1999.

9. Mitrofanov F.P., Pozhilenko V.I., Smolkin V.F., et al. (ed. Mitrofanov F.P). Geology of the Kola Peninsula (Baltic Shield). Apatity. KSC RAS. 1995. 145 p.

10. Nitkina E.A., Kaulina T.V. Age and composition of rocks of the eastern frame of the Pechenga structure, Kola region // IOP Conference Series: Earth and Environmental Science (EES). 2019. В печати. 